\title{
Lesbian, Bisexual and Queer Motherhood: Crafting Radical Narratives and Representing Social Change through Cultural Representations
}

\author{
This article examines how lesbian, gay, bisexual and queer (LGBQ) women negotiate \\ mother identity narratives through critical engagement with diverse media \\ representations. I draw on the reported experiences of LGBQ mothers living in Great \\ Britain, collected in semi-structured, in-depth qualitative interviews during 2013 and \\ 2014. Interview data is used to examine how queer and social-radical positions are \\ articulated through, and to explore LGBQ women's relationship to, the identity of \\ mother and its attendant traditional gender role. The LGBQ women I spoke with \\ identified a range of representations drawn from sources including graphic novels, \\ children's books, and television, as significant in their negotiation of mother identities. I \\ argue LGBQ women's selection and usage of representations illustrates their deliberate, \\ conscious and ideologically driven negotiations of cultural images and indicates the \\ way in which media is central in articulating mother identities. \\ I conclude by suggesting that traditional images of motherhood, and the existing \\ vocabulary of mothering, are radically redeployed by women whose identities fall \\ outside of the heteronorm. Further, I demonstrate that the use of existing \\ representations of motherhood to describe different non-heterosexual mother identities \\ is a key way in which LGBQ women model social change and seek to circulate \\ alternative, validated narratives of motherhood.
}

Keywords: LGBQ mothers, media images, negotiated reading, social change, radical, non-heterosexual, mothering, representation

\section{Introduction}

I have no connection to the identity of Mother... There's so much culturally about motherhood that to me is both negative and even when it's positive, it's positive in a way that I don't find positive... When people say [Mother] I feel a bit weird inside. It just feels quite jarring; it feels like being called by someone else's name. (Charlie, bisexual woman, 2013)

This article examines how lesbian, gay, bisexual, and queer (LGBQ) women living in Great Britain negotiate mother identities. In the quotation above, one of the research participants, Charlie, suggests that the designation mother carries a number of cultural and gendered 
Reed, Elizabeth (2018)

meanings. These various meanings are reiterated and [re]circulated through various representations in media and culture. Dominant discourses or ideologies of motherhood offer a narrow definition of what constitutes maternal practice (Gibson 2014: 6; Ruddick 1989: 29; Skeggs 1997: 20). A number of scholars have elaborated the specific demands these discourses make upon mothers. These constitute what I am calling motherhood-imperatives and include: an insistence on mothers to sustain and support the patriarchal order (Kaplan 1992: 4; Rich 1986 [1976]: 43); the positioning of motherhood as inevitably heterosexual (Gabb 2005a: 4212; Sardadvar and Miko 2014: 142; Skeggs 1997: 120); demands for the performance of proper, middle-class femininity (Rich 1986 [1976]: 25-6; Skeggs 1997: 115-7; Wallbank 2001:41); and the stabilisation and continuity of nuclear families (and cohesive social structure) made possible by good motherhood (Skeggs 1997: 44; Wallbank 2001: 38-9).

Charlie's broad rejection of the identity of mother in the quotation above is, therefore, socially significant and culturally located. She rejects not just the title mother, but the cultural and social imperatives (catalogued above) which are tied up with it and specify how she should look and behave. As I will show, she, and other women who participated in this study, articulate their queer subjectivities and challenge social norms through their negotiation of the meanings and imperatives of the institution of motherhood (Rich 1986 [1976]: 39-42).

Whilst considerable scholarship has been dedicated to examining the meanings and availability of representations of LGBTQ people generally (Bersani 1989; Doty and Gove 1997; Driver 2007; Dyer 1990; Gross 1994; Woods 2009) and, more recently, representations of LGBTQ people parenting (Cavalcante 2015; Hicks 2011; Walters 2012), little attention has been paid to how narratives of motherhood which [re]emerge in media and cultural representations relate to, and help constitute, culturally-resistant subjectivities (Gibson 2014). This article offers a perspective on how LGBQ women respond to the motherhood imperatives 
identified in the research summarised above and the role of representations in helping LGBQ mothers circulate and consolidate alternative narratives of motherhood.

\section{The Study}

This article draws on qualitative data collected during in-person interviews with nineteen cisgender (people whose gender identity is the same as the one they were assigned at birth) LGBQ women, conducted during 2013 and 2014. This data is part of a larger research project exploring the experiences of LGBTQ+ parents as they negotiated family identities through and in a media culture saturated with narratives of a narrow range of family-types. In an attempt to document the experiences and perspectives of a broader range of families, participants were recruited through a combination of snowball and purposive sampling. Participant ages range from 26-49 and include British, Welsh, Scottish, Irish, European, and American women, all of whom were living in Scotland or England at the time of our interview. Despite this flexible approach to recruitment, the sample I refer to here is largely homogenous in terms of race and class. Only one participant described herself as something other than middle-class, and all participants described themselves as white.

In research such as this, Taylor cautions that too often, white middle-class experience is produced as the universal queer subjectivity because of the over-representation of these people in existing studies (2010: 70). I note, therefore, that this study should not be considered representative of all LGBQ women, or even all LGBQ mothers. Indeed, Weston suggests that achieving this is impossible for a 'population [which] is not only partially hidden or closeted but also lacks consensus as to the criteria for membership' (1997: 9). Rather, this paper offers a snapshot of the lives, experiences, and media interactions of a given group of people who are diverse in some respects (age, location, nationality, experience) and homogenous in others (race, class). 
The various cultural and media representations which this paper examines were all identified by participants as significant in their negotiation of mother identities. I do not suggest that I present a comprehensive review of material which represents LGBQ women or which concerns the meanings of motherhood. Rather, this approach to selecting representations prioritizes those narratives which were most relevant to the women I spoke with, and with which they had significant relationships.

\section{Context}

Rich describes the institution of motherhood as "the foundation of human society as we know it, [allowing] only certain views, certain expectations" (1986 [1976]: 39). Further, she suggests it "prescribe[es] a limited set of possibilities for women" which sustain patriarchy and reproduce "this constricted version of humanity, which one generation transmits to the next" (1986 [1976]: xxxvi). The dominant meanings of motherhood, and the ways in which women who mother become visible and validated in culture are, Rich argues, rigidly policed (1986 [1976]). By contrast, non-heterosexual lives are widely theorised as offering space for radical and original ways of living that challenge the primacy of patriarchal and heterosexual structures in social life (Bersani 1989; Edelman 2004; Halberstam 2005; Muñoz 2009). Families formed by LGBTQ people and their practices of care-work have been singled out as having uniquely disruptive and socially creative possibilities (Breshears 2010; Weeks, Heaphy \& Donovan 2001; Weston 1997). How non-heterosexual women who parent experience these seemingly contradictory narratives of their roles and identities is the central focus of this article. Rich suggests that the practices of mothering may be experienced very differently to the way in which the institution of motherhood describes this role. But can the politics and experiences which LGBQ women bring to their mothering practice offer a route to destabilise the primacy 
of the institution of heterosexual motherhood and 'break the cycle' (Rich 1986 [1976]: xxxvi) of its repetition and control?

\section{Findings}

During semi-structured interviews which took place in homes, cafes, and workplaces, I asked participants to tell me about how they made decisions about what to call themselves when they became parents and what helped them make these choices. In response, all of the LGBQ women I spoke with told me about their negotiation of the title of 'mother'. It is this significant theme from the interview data which I explore here, with particular reference to the tension between the conflicting narratives of what possibilities are allowed by the institution of motherhood and what possibilities are enabled by non-heterosexual lives. This key theme is further divided and responses are collected under the subheadings which follow.

I move from discussion of how some women refused the title 'mother' and its associated gender role[s] in refusing maternal imperatives to consider the anxiety of claiming mother, which some women expressed. I further consider how LGBQ women blend narratives of their mother identity with their pre-existing and evolving queer identities and politics. By asking women to return to the question of how they make decisions about what to call themselves, and what resources they used to support their evolving narratives of identity as mothers, I consider how motherhood is constructed through engagement with representation and the specific elements of LGBQ motherhood which these women wished to celebrate and make visible. As I will show, LGBQ women negotiate motherhood through a range of cultural resources, and motherhood [re]emerges as a flexible and potentially enabling institution.

\section{Refusing Maternal Imperatives}


I asked participants how they chose which names they would use at home. A number of participants rejected the social expectation that, as women performing parenting roles, they would be a mother. As Jelena put it: 'I never wanted to be a mummy, I wanted to be a parent, but not a mummy' (Jelena, lesbian woman, 2013). These participants preferred instead to craft alternative titles for themselves, which articulated their role outside of traditional scripts of motherhood and emphasized 'families as process' (Gabb 2005b: 586). For example, Jelena's partner, Hannah, birthed their two daughters. Jelena highlighted her different reproductive role in their family as significant in her decision not to be called 'Mummy':

I didn't want to have them [give birth] physically, in spirit I give them everything. Physically I did not want to have that so therefore they just [call me by] my name. The distinction in here is that I am parent, I want to be that, and I am that, and I will always be that; not Mummy. (Jelena, lesbian woman, 2013)

Jelena was divorced from pregnancy and childbirth, and this played a significant role in how she defined her place within her family and chose the name her daughters would use for her. She emphasizes the significance of childbirth in determining who can be 'mother' and locates her identity firmly outside this framework.

Jelena also invoked discourses associated with traditional maternal actions and beliefs when describing her role in the home and her feelings about being a parent: 'I feel protective and I want a better life for my children... I feel more responsible as a human being' (Jelena, lesbian woman, 2013). I suggest this comment indicates her resistance to a binary conception of parental identities where only progenitor categories (Gabb 2005b: 600) are discursively produced as significant and other roles are viewed as peripheral to the construction of family.

Some women I spoke to had experience of pregnancy and childbirth but, like Jelena, did not use the title of mother. Charlie described herself as ill-at-ease with cis-female identity and maintained a critical distance from the identity of mother, which she characterized as 
strongly gendered. Instead, Charlie and her male partner Jamie made up light-hearted alternative titles which described their actions, rather assigning specific gender roles:

Charlie: We made up our non-gendered parent terms during pregnancy - vessel parent and fetching parent!

Jamie: I get to be fetching parent.

Charlie: I like 'fetching parent' because fetching parent is utterly non-gendered and it doesn't even require any kind of biological relationship but I regard that a large part of the work of a parent who doesn't have to be pregnant is doing an awful lot of fetching so, um, that was our kind of semi-serious self-descriptions because we didn't really like 'mother' and 'father' and 'dad' and those sort of things, and we preferred those and we thought they were quite entertaining.

(Charlie, bisexual woman and Jamie, bisexual man, 2013)

By offering alternative titles for established parenting roles, Charlie insisted on a description of her identities and actions that was disentangled from binary gender roles and constructions of motherhood which rely on essentialist descriptions of the supposed innate skills of women (Rich 1986 [1976]: 12; Sardadvar and Miko 2014: 145). Charlie's response to what she perceived to be the restrictively gendered role of mother was to reject it in order to create space for a new exploration of her role as a parent. Further, her critical response and newly created narrative of parental identity disrupts the cultural expectation that people in heterosexualappearing relationships conform to traditional models of motherhood and parenthood (Sardadvar and Miko 2014: 150). Rich describes how the institution of motherhood creates 'prescriptions and conditions in which choices are made or blocked', which shape 'the circumstances of our lives' (1986 [1976]: 42). Charlie's response indicates how individuals might offer resistant responses to the pervasive assumptions of heterosexual conformity which accrue around women enacting parenting roles by renouncing both the title of mother and the prescriptions which accompany it. 


\section{The Anxiety of Claiming 'Mother'}

For a number of participants I spoke to, it was claiming mother as an identity, not rejecting it, which generated anxiety, discomfort, and prompted critical reflection on its meanings and uses. Participants who did not have a reproductive, or progenitor, relationship to their children related experiences of prejudice and marginalization stemming from their decision to be called mother. Mother was a desirable title for many women because it offered legitimation for their role and located them within the culturally intelligible framework of family (Gabb 2005b; Mason 1994: 141). However, the possibility of claiming the title was not equally available.

Emily and Isabel, a same-sex couple, reported that their attempt to claim mother was rigorously policed by heterosexual extended-family members. They described how Emily's mother refused to acknowledge Emily as 'Mum' because she did not have a reproductive role. Emily and Isabel located Emily's mother's discomfort in their disruption of social (heterosexual) norms, and the threat they posed of making her visible as a mother who has 'failed' to produce a properly heterosexual daughter; who, in turn, has failed to contribute to the succession of heterosexual family and motherhood norms (Ahmed 2010: 11, 17-8).

Emily: My Mum was a bit prejudiced wasn't she? Mum wrote me letters saying that [I] definitely shouldn't be called Mum, and she still doesn't call me Mum with [our daughter] Lucy, I noticed... and she won't tell any of her friends so although she's a doting Grandma and I'm the only child Isabel: She hasn't told anybody. Emily: She hasn't told any of her friends... So when we go down there and Lucy says 'hi Granny'... if the next door neighbours heard, I don't know what she'd do.

(Emily, bisexual woman, and Isabel, lesbian woman, 2013)

Emily's mother attempted to encourage Emily to adopt a title which would make her [queer] relationship with Isabel less visible, and which discursively separated her from the established meanings of the language of family. Skeggs suggests this type of pushback is common when an individual or group, instead of 'operating as the constitutive outsider' works from 'proximity 
Reed, Elizabeth (2018)

within the space, disrupting safety [or security of heterosexual family], comfort and home' (Skeggs 2005: 966). It is therefore precisely their decision to jointly claim the title mother without embracing a heterosexual family arrangement which brings Emily and Isabel into conflict with their extended family.

Emily's struggle to be legitimated as a mother to Lucy illustrates the 'struggle [for] recognition, and the privilege to narrate oneself (rather than to be narrated by others)' experienced by many LGBQ mothers and 'reflects wider dimensions of social, cultural and economic status' (Thomson et al. 2011: 9; see also Weston 1995: 93). The challenges associated with claiming the title of mother illuminate the continued cultural significance of the role of mothers and the social power imbalance that preferentially recognizes women as mothers if they have birthed their children and conform to heterosexual life courses. Returning to Charlie's rejection of the title of mother quoted at the beginning of this article, I suggest her refusal can also be understood as an act of solidarity with women in same-sex couples who cannot access the title of mother as easily as she can. Refusing to be mother presents a critique of the automatic intelligibility and right to claim the title of mother which women in heterosexual-appearing couples experience when they have children.

Women in non-heterosexual relationships represent a threat to the logic that produces the heterosexual family, which dictates that mothers must be co-constituted by a father before their production of family can be validated (Thomson et al. 2011: 31). The borders of mother as an identity are closely regulated through intergenerational communication and the transmission of the heterosexual-authorized meanings of mother. Being 'mother' whilst identifying outside of the heterosexual framework which legitimates mothers may also be considered a statement of resistance. The new narratives of motherhood and claims to legitimacy as mother for women in non-reproductive roles 'struggle' against 'older discourses, causing a general shake-up, disruption, dislocation' (Kaplan 1992: 14). As I discuss below, the 
women I spoke to sought to stabilize their narratives of non-heterosexual motherhood in this 'struggle' through their engagement with culturally validated representations.

\section{Motherhood as Queer Practice}

Whilst Emily and Isabel found their negotiation of mother identities was fraught and constrained by the traditions of heterosexual motherhood, other women I spoke with identified those same traditions as a key reason they wanted to take on the title of mother. Julia, a lone parent, described motherhood as offering a way to present 'strong female role model[s]' to her daughter Niamh:

I want to be Mummy, yes, absolutely want to be Mummy. My Mum was Mummy, I want to be Mummy... my Mum was a single parent as well... I know [Niamh]'s going to grow up with at least one strong female role model because my Mum provided that for me and I'll provide that for her. (Julia, queer woman, 2013)

For Julia, motherhood and being 'mummy' was enabling. By taking on this role she was able to locate herself within a women's heritage of creative and empowered responses to childrearing. Julia suggests the work of offering alternative or resistant models of femininity is integral to being a mother; in this way she 'eases the conflict' prompted by 'blurring the lines of personal and political responsibility' (Wrigley 1998: 264) which might otherwise attend a politicized narrative of motherhood. Julia, like most of the other women I spoke with, implicitly recognized motherhood as a flexible institution which offered space for resistant practices (Collins 2000: 207-9; Kaplan 1992: 10) and indicated her hope to use this space to articulate queer possibilities and responses.

The sense of possibilities of motherhood being enabled by experiences which attend queer life courses (see also Gibson, 2014: 1-5) was something the women I spoke to indicated 
in their reflections. Joanne was in a same-sex relationship and was a mother to one daughter. She described how she sought to parent her daughter:

it's more about actively trying to be non-normative, actively trying to break the boundaries, trying to work at that as a resistant practice... like we won't dress her in pink, we really push against the gendered stereotypes, we try really hard to throw her in the air all the time, we try really hard not to give her dolls... because we want her a bit, I guess, just to experience what it's like to be treated like a boy and treated like a girl. (Joanne, lesbian woman, 2013, participant's emphasis)

Experience of social communities of non-heterosexual women which celebrated and enabled alternative performances of gender informed the narratives of gender which these mothers presented to their children.

Similarly, Hannah spoke about how her experience growing up as a lesbian woman had prompted her to reflect on gender inequalities in society. She explained that this now informed her practice as mother to two daughters: 'I always used to think lesbians are more politicized in a way because of the way we've had to grow up ourselves, so [we] try to have discussions about gender and thinking about the toys [they play with]' (Hannah, lesbian woman, 2013).

For both Hannah and Joanne, the experience of occupying non-heterosexual subjectivities informed the decisions they made to disrupt restrictive gender roles and promote boundary breaking. Being located outside the expected subjectivity of motherhood opens space for LGBQ women to trouble 'unstable boundaries' and consider 'how relationships, communities, genders and sexualities might otherwise proceed' (Gibson 2014: 2, 6).

Non-heterosexual identity is therefore implicated in prompting new responses to motherhood and a reconfiguring of the presumed heterosexual-family-making role of the mother. These women draw together their imaginative resources, accrued through cultural and social participation in queer and lesbian women's communities, and offer models of mothering practice which promote different possibilities for gender and identities. 


\section{Making Motherhood Through Representations}

Dyer (1990) argues that the resources for telling stories of self come from culture. Thus, 'cultural productions [...] limit what can be said but also make saying possible; they both form and deform all expression' (1990: 1). Dyer proposes that, especially for queer people, representation is an important way in which alternative and resistant identity narratives can be sustained (1990: 286). I look now at the resources the women I interviewed identified as important in both helping them produce new narratives of motherhood and allowed them to locate themselves as mothers in the cultural world. I argue that these practices of narrativemaking with existing representations are key in how these women seek to generate culturally significant and lasting narratives of non-heterosexual motherhood.

I asked participants whether they felt any representations offered narratives of nonheterosexual motherhood. Some of the women I spoke with described the resistant and negotiated reading techniques (Hall 1980) they used to 'discover' queer meanings 'lurking behind the text's apparently heterosexual surface' (Innes 1997: 123). Mary, a bisexual mother to one son, described an episode of The Clangers entitled 'The Egg' (Postgate and Firmin 1970). Mary celebrated its representation of motherhood as something that can be built and supported by a community, rather than emerging from a traditional parenting dyad. In 'The Egg', the Clangers rally around a downhearted Soup Dragon by seeking the help of the Iron Chicken to gather materials to make and hatch an egg. After being zapped with the Iron Chicken's laser, a baby soup dragon hatches and the Soup Dragon and Clangers celebrate.

Mary and her partner Paul describe themselves as poly, a term short for polyamory which describes having multiple concurrent consensual sexual and romantic relationships (Sheff 2014: xiv-xv). The Clangers' collaborative approach to facilitating the Soup Dragon's wish to be a mother reflected Mary's experience in which Paul, her second partner Matthew, 
and Matthew's partner Sandra all worked in different ways to support her in becoming a mother. The Clangers therefore offered representation of mothering as an activity that can be enabled by groups of people outside of the nuclear family arrangement, and outside of monogamous romantic relationships.

Charlie, whose comments I explored above in relation to her complex response to the title of mother, discussed the graphic novel series Saga (Vaughan and Staples 2012-present). She described it as a text which 'you can read as very queer [...] there are a lot of queer themes to it [even though] it isn't ostensibly about queer issues' (Charlie, bisexual woman, 2013). Saga follows Alana and Marko, an interspecies couple, and deserters on the run from their respective armies. Despite both the cultural differences of their respective species (built on a centurieslong intergalactic war between their people) and their divergent evolution, Alana and Marko have a child named Hazel. Charlie singled out this text as offering a representation of maternity and motherhood which celebrated Alana for being independent and skilled, and showed her experiencing maternity as something which intensified her strength.

The image used on the cover of the first collected volume of Saga (Vaughan and Staples 2012) shows Alana with one breast exposed, as she nurses baby Hazel, holding a gun in her free arm. She is looking directly at the reader, seemingly challenging onlookers to object to her visible maternity. The image references both traditional maternal imagery-Alana nurtures Hazel at her breast—and also offers signs of traditional masculinity - the gun she holds casually by her side, and her direct, confident stare. This offers precisely the image of parenting - and mothering - which Charlie indicated she sought to articulate in her own identity narrative. It combines multiple signals of gender and represents motherhood as something a parent does alongside her other identities and in negotiation with her other responsibilities, and not as a role which subsumes or negates other articulations of identity. 
Reed, Elizabeth (2018)

Further, the choice to have an image of Alana nursing Hazel on the cover of this volume was described by writer Vaughan and graphic artist Staples as an explicit statement against contemporary controversy around women breastfeeding in public, and as a feminist political statement (Gilly 2014; Meylikhov 2014). Alana's representation is one of resistance; this is a woman who will not be quiet, invisible, or shamed into a discreet performance of maternity. In the contemporary social climate, and in the wider narrative of Saga, breastfeeding itself is resignified as a socially radical act, rather than an image of conformity to traditional motherhood. Charlie's identification with, and celebration of, this graphic novel firmly located her, and her parent-identity, as a willing cultural threat and uncompromising advocate of new narratives of motherhood.

\section{Celebrating Multiple Mothers}

One text referred to by a number of women, which offered images of non-heterosexual motherhood that did not require queer reading strategies to access, was If I Had 100 Mummies (Carter 2007). The book follows a young girl as she daydreams about what it would be like to have one hundred mummies instead of, we learn at the end of the book, the two she currently has. On one page, the illustrated book depicts a line of women queuing up to give the girl a kiss goodnight; they are dressed in an array of styles and appear to have a variety of occupations, from witch to nun, suffragette to clown, explorer to academic. Their clothing covers a range of eras and references both historical figures, such as Vita Sackville-West and Virginia Woolf, and fictional characters, such as Alice from Alice in Wonderland. Figures are both human and non-human - there is a queen of hearts playing cards and an octopus - and ordinary and extraordinary - a large woman in a green cardigan rubs shoulders with a twodimensional Cleopatra. 
Reed, Elizabeth (2018)

If I Had 100 Mummies represents women — potential mothers to the central characteras diverse, capable of many professions and many varied caring actions, and equally valuable. In this respect, the book fulfilled two key elements of representation which the women I spoke with described as significant in their articulation of mother identities. Firstly, it represents LGBQ women as capable and desirable mothers. There are nods to lesbian and feminist histories of non-conforming and explicitly political women in, for example, depictions of the suffragette, Woolf, and Sackville-West. These offer validation and recognition of what such women can offer as mothers. This was significant for many of my participants, who felt that non-heterosexual, feminist, and gender-non-conforming women were frequently absent in the media or depicted as being inadequate mothers.

Participants suggested this negative trope in representation hinged upon the lower cultural value associated with women who do not perform traditional femininity, and women who were visually coded as non-heterosexual:

lesbian parents still get marginalized in [media] and they get kind of forgotten about... Lesbian parents are represented as slightly femme looking women and there's an awful lot of butch lesbians having kids and they are beautiful people too... I just think that same-sex women who are in relationships are a very diverse looking group and they need to be represented across that diversity (Ivy, lesbian woman, 2014)

In If I Had 100 Mummies, the diversity of women considered as potential mothers is central to the playful plot, as the protagonist contemplates how her life would be changed by the different skills and interests each woman could bring. In this respect, the book offered a valuable resource to support and validate narratives of legitimacy which the women I spoke with sought to offer their children.

Secondly, the book was celebrated for representing mothers and motherhood as multiple; there is not one way to be an LGBQ mother, there is not one occupation or common physical feature which they all share. If I Had 100 Mummies addresses a great range of LGBQ 
mothers in one text. This was especially valuable, given how many women said they saw no representation of mothers like them. Emily and Isabel offered an example of how having two mothers had prompted their daughter and her friends to consider the possibilities of having multiple mothers instead of just one:

Isabel: Then there was a phase where sort of her friends thought it was cool that she had two Mums.

Emily: [they were] quite jealous, a lot of them went home and said 'why can't we have two Mums?'!

(Emily, bisexual woman, and Isabel, lesbian woman, 2013)

Multiple mothers are represented in this book as something that is not just desirable, but uniquely offered by LGBQ women. This corresponds with Emily and Isabel's account of their daughter's friends only considering the possibility of having more than one mother after encountering them.

In the above examples, there is a common theme of representations that offer expanded narratives of what motherhood can involve and how it can be enacted. Diverse representation therefore offered two key advantages: first, a framework in which women could locate their own experiences of being 'mother' outside heteronormative expectations; and second, a way to circulate and share alternative and diverse narratives of being 'mother' through a culturally located and widely accessible platform.

\section{Making Social Change Through Motherhood}

Many of the women I spoke to discussed the ways in which they felt motherhood could enable new possibilities. José Esteban Muñoz suggests that queer practice describes the drive to 'dream and enact new and better pleasures, other ways of being in the world, and ultimately new worlds' (2009: 1). Through the telling and sharing of stories like those highlighted above, and by offering new models for inhabiting traditional roles and recrafting specific gender roles, 
the women I spoke to hoped that they were passing on something new and enabling their children to explore different life courses. Eva reflected on the things she hoped to introduce her son to as he grew older:

I want him to be familiar with the freedom that comes with being gay... You can kind of have your sexuality as you want it, and sexuality is integrated into living, and the book stores where you get your intellectual books are the same places you get your sex toys, and I like that it's not puritanical, and I like that this is very open... I would want him to know, to be that open with regards of his sexuality because it's a much more fulfilling way to live life (Eva, lesbian woman, 2013)

Goss suggests that the desire of LGBTQ people to have a family is "not an assimilationist strategy of finding respectability', but is rather 'queering the notion of family and creating families reflective of [their] life choices' (1997: 12). Certainly, Eva's aim-to integrate the experiences and community links connected to her lesbian identity into her mothering practice - suggests that she is queering the possibilities of traditional heterosexual motherhood. Eva integrates the cultural and social elements associated with LGBTQ identity, which she values, into an otherwise traditional, 'respectable' production of mothering connected with socialising and educating children (Skeggs 1997: 45-7). Her narrative of the usefulness of this view of sexuality for her son's development successfully blends the imperatives of the institution of motherhood to train and orientate children with queer activist positions that celebrate sexual outsiderhood and permissive narratives of sexuality.

Lynne described how she employed queer reading practices, both to address her own need for representation and as a way to help expand her daughter Zoë's imaginative world and highlight the invisible presence of non-heterosexual people in all parts of society.

There weren't books, child[ren's] books, that would reflect my family... I remember reading books and thinking 'oh god, this is so heterosexual', so I would, when reading books, say [to Zoë] 'this isn't how all families are'... like [I would say] 'that person, who 
knows? They might be bisexual, they might have a trans history, we don't know, do we?' It's not explicit, but I would put it in there. (Lynne, bisexual woman, 2013)

Through her story-telling, and by repeatedly highlighting her bisexual identity to her daughter, Lynne modelled motherhood which does not reproduce heteropatriarchy but offers legitimation of alternative sexuality and gender performances. Lynne's articulations of her mother identity, as shaped by her bisexual identity, were made possible through access to and ownership of material in which she could either insert narratives of non-heterosexual identity or explicitly display around the home as conversation points and visual reminders of her non-heterosexual identifications. It was in this way that Lynne undertook the work of building a home, a key element of traditional maternal practice and heterosexual family-making (Gorman-Murray 2007: 196-8). She shaped her home with explicit reference to queer identity, queer cultural productions, and markers of socially radical or activist engagement. She noted Stonewall campaign postcards on her fridge as one example of this. Lynne indicated she believed the resulting space enabled her daughter to explore a broader range of life-course options.

The cumulative effect of these various mothering practices, which both conform to and queer the expectations and prescriptions of motherhood imperatives, and narratives of what LGBQ motherhood may mean, was that these women felt their various day-to-day engagements represented 'radical acts':

Just being a gay family, there's a radical act in that really (Hannah, lesbian woman, 2013)

You're doing something different... There's not one way to change the world. If it is possible to change the world anyway. There isn't one way to do it and the fact these girls [her daughters] will go out and be confident saying 'I came from a gay family' will touch upon people that gay activists won't touch on. I don't march anymore... That's not to say you shouldn't fight to change things but there's more than one way to skin a cat. (Harriet, lesbian/queer woman, 2013) 
I went to the school fete instead of going to gay pride... I think actually in some ways I'm doing something as political by being on the bric-a-brac stall at the primary school fete than I am marching on the streets of gay pride. It's a different type of politicism, isn't it, by just being visible, and we are very visible. (Emily, bisexual woman, 2013)

Sara Ruddick suggests that it is difficult for mothers to articulate resistance and have their actions understood as resistant acts, because all of their actions are inevitably, inescapably, read through the lens of maternal responsibility, expectation, and conformity (Ruddick 1989: 222-9, see also Gibson 2014: 6). The women I spoke with explicitly rejected normalising readings of their maternal practice, when they insisted on the radicalism of their visible lives as non-heterosexual mothers. They compared this self-evaluated radicalism to traditional modes of activist and radical engagement, such as the protest march Harriet and Emily make reference to, in order to firmly establish their mother identities as politically significant. Blee reminds us that 'an action may be radical in one context but not in another' (1998: 3). The emphasis these women placed on their visibility as non-heterosexual mothers in the institutional context of school and in the broader heterosexual community illustrates the places and ways in which mothering can be reconstituted as a radical act.

Patricia Hill Collins, writing about socially and economically disempowered black women, suggests that 'participation in a constellation of mothering activities, collectively called motherwork, often foster[s] a distinctive political sensibility' (2000: 209). The constellation of mothering activities, which the women I spoke to engaged in, generated a sense of purpose and radical potentiality. These women located their LGBQ identities as significant in re-making and re-narrating the role of mothers, and they worked to circulate narratives which celebrated diversity in women who mother, offering a range of models for engaging in 'motherwork'.

\section{Conclusion}


The women I spoke to reproduced many traditional elements of mothering, with some choosing to use both the title and vocabulary of motherhood and many arranging their lives to prioritize care of children. However, the reproduction of traditional elements of motherhood was done with critical reflection and in conjunction with consciously chosen and articulated queer ideologies. These women took time to acknowledge the value of their LGBQ identities in responding to existing narratives of motherhood and in helping them find ways to craft new and flexible mother identities. They offered clear narratives of the significance of being LGBQ mothers and of the social import of the 'radical' visibility of their families.

Representations were central in the work these women did. Representations offered routes for these women to access validation and reassurance that their resistant or critical responses to motherhood were supported in popular cultural forms. The women I spoke with were conscious of the way in which such material circulates ideas and the opportunity it offered to communicate different models of family and mothering.

These LGBQ women were engaged in dialogue with heterosexual imperatives of motherhood. Their various responses to those imperatives indicate an attempt to shift or trouble dominant discourses of motherhood in order to enable greater possibilities and more varied productions of culturally validated mother identities. Through a cultural reservoir of representations, which they curated and shaped, and through their individual identity narratives, these women generated new possibilities for motherhood. Whilst I do not suggest that the shift to more widely available, culturally permissive narratives of motherhood and parental roles for women will be swift, I do argue that the labour these women put into developing and circulating new narratives and into facilitating alternative gender roles at home, through and by engagement with representations, is socially and culturally significant. 
Reed, Elizabeth (2018)

Acknowledgements: This work was supported by an Arts and Humanities Research Council PhD Studentship Award.

\section{Works Cited}

Ahmed, Sara. (2010) The Promise of Happiness. Durham: Duke University Press.

Bersani, Leo. (1989) 'Is the Rectum a Grave?' In Douglas Crimp (ed.) AIDS: Cultural Analysis, Cultural Activism. London: MIT Press, pp.197-222

Blee, Kathleen M. (1998) 'Women on the Left/Women on the Right'. In Kathleen M. Blee (ed.) No Middle Ground: Women and Radical Protest. New York: New York University Press, pp.1-15.

Breshears, Diana. (2010) 'Coming Out with Our Children: Turning Points Facilitating Lesbian Parent Discourse with Their Children About Family Identity'. Communication Reports 23(2), pp.79-90

Carter, Vanda. (2007) If I Had 100 Mummies. London: Only Women Press.

Cavalcante, Andre. (2015) 'Anxious Displacements: The Representation of Gay Parenting on Modern Family and The New Normal and the Management of Cultural Anxiety'. Television and New Media 16(5), pp.454-471.

Collins, Patricia Hill (2000) Black Feminist Thought: Knowledge, Consciousness, and the Politics of Empowerment (2 ${ }^{\text {nd }}$ edn.), New York: Routledge.

Doty, Alexander and Ben Gove (1997) 'Queer Representation in the Mass Media'. In Andy Medhurst and Sally Munt (eds.) Lesbian and Gay Studies: A Critical Introduction. London: Cassell, pp.84-98

Driver, Susan (2007) Queer Girls and Popular Culture: Reading, Resisting, and Creating Media. New York: Peter Lang.

Dyer, Richard (1990) Now You See It: Studies on Lesbian and Gay Film. London: Routledge. 
Reed, Elizabeth (2018)

Edelman, Lee (2004) No Future: Queer Theory and the Death Drive. Durham: Duke University Press

Gabb, Jacqui (2005a) 'Locating Lesbian Parent Families: Everyday Negotiations of Lesbian Motherhood in Britain'. Gender, Place and Culture 12(4), pp.419-432.

— — - (2005b) 'Lesbian M/Otherhood: Strategies of Familial-Linguistic Management in Lesbian Parent Families'. Sociology 39(4) 585-603.

Gibson, Margaret F. (2014) 'Introduction'. In Margaret F. Gibson (ed.) Queering Motherhood: Narrative and Theoretical Perspectives. Bradford: Demeter Press, pp.1-26.

Gilly, Casey (2014) 'Brian K. Vaughan on the Expanding Universe of "Saga", Comic Book Resources, 20 November, at http://www.comicbookresources.com/?page $=$ article\&id=57233 (accessed 11 August 2016).

Gorman-Murray, Andrew (2007) 'Contesting Domestic Ideals: Queering the Australian Home'. Australian Geographer 38(2), pp.195-213.

Goss, Robert E. (1997) 'Queering Procreative Privilege: Coming Out as Families'. In Robert Goss and Amy Adams Squire Strongheart (eds.) Our Families, Our Values: Snapshots of Queer Kinship. London: Harrington Park Press, pp.3-20.

Gross, Larry (1994) “"What is Wrong with this Picture?” Women and Gay Men on Television'.

In R. Jeffrey Ringer (ed.) Queer Words, Queer Images: Communication and the Construction of Homosexuality. London: New York University Press, pp.143-156

Halberstam, Jack (2005) In a Queer Time and Place: Transgender Bodies, Subcultural Lives, London: New York University Press.

Hall, Stuart (1980) 'Encoding/Decoding'. In Stuart Hall (ed.) Culture, Media, Language: Working Papers in Cultural Studies. London: Hutchinson, pp.128-138.

Hicks, Stephen (2011) Lesbian, Gay and Queer Parenting: Families, Intimacies, Genealogies. Basingstoke: Palgrave Macmillan. 
Reed, Elizabeth (2018)

Innes, Sherrie A. (1997) A Lesbian Menace: Ideology, Identity and the Representation of Lesbian Life. Amherst: University of Massachusetts Press.

Kaplan, E. Ann (1992) Motherhood and Representation: The Mother in Popular Culture and Melodrama. London: Routledge.

Mason, Angela (1994) 'The Scientific Baby and the Social Family: The Possibilities of Lesbian and Gay Parenting'. In Emma Healey and Angela Mason (eds.) Stonewall 25: The Making of Lesbian and Gay Community in Britain. London: Virago, pp.137-149.

Meylikhov, Matthew (2014) 'Saga Courts “Controversy” On Purpose with New Hardcover', Multiversity Comics. 29 July, at http://www.multiversitycomics.com/news/saga-courtscontroversy-on-purpose-with-new-hardcover/ (accessed 11 August 2016).

Muñoz, José Esteban (2009) Cruising Utopia: The Then and There of Queer Futurity. New York: New York University Press.

Postgate, Oliver (writer) and Peter Firmin (director) (1970). 'The Egg', The Clangers. Canterbury: Smallfilms.

Rich, Adrienne (1986 [1976]) Of Woman Born: Motherhood as Experience and Institution. London: Virago Press.

Ruddick, Sara (1989) Maternal Thinking: Towards a Politics of Peace. London: The Women's Press.

Sardadvar, Karin and Katharina Miko (2014) 'Shifting Families: Alternative Drafts of Motherhood'. In Margaret F. Gibson (ed.) Queering Motherhood: Narrative and Theoretical Perspectives. Bradford: Demeter Press, pp.141-158.

Sheff, Elisabeth (2014) The Polyamorists Next Door: Inside Multiple-Partner Relationships and Families. Plymouth: Rowman and Littlefield Publishers.

Skeggs, Beverley (1997) Formations of Class and Gender: Becoming Respectable. London: Sage. 
_ _ _ (2005) 'The Making of Class and Gender through Visualizing Moral Subject Formation'. Sociology 39(5), pp.965-982.

Taylor, Yvette. (2010) ‘The “Outness” of Queer: Class and Sexual Intersections'. Kath Browne and Catherine J. Nash (eds.) Queer Methods and Methodologies: Intersecting Queer Theories and Social Science Research. Farnham: Ashgate, pp.69-84.

Thomson, Rachel, Mary Jane Kehily, Lucy Hadfield, and Sue Sharpe (2011) Making Modern Mothers. Bristol: Policy Press.

Vaughan, Brian K. (writer) and Fiona Staples (artist) (2012) Saga. Volume One. \#1-6. Image Comics.

Wallbank, Julie A. (2001) Challenging Motherhood(s). Harlow: Pearson Education.

Walters, Suzanna Danuta (2012) 'The Kids Are All Right but the Lesbians Aren't: Queer Kinship in US Culture'. Sexualities 15(8), pp.917-923

Weeks, Jeffrey, Heaphy, Brian, \& Donovan, Catherine (2001) Same Sex Intimacies: Families of Choice and Other Life Experiments. London: Routledge

Weston, Kath (1995) 'Forever is a Long Time: Romancing the Real in Gay Kinship Ideologies'. In S. Yanisako and C. Delaney (eds.) Naturalizing Power: Essays in Feminist Cultural Analysis. New York: Routledge, pp.87-107

_ _ _ (1997) Families We Choose: Lesbians, Gays, Kinship (2nd Edn). New York: Columbia University Press.

Wrigley, Julia (1998) 'From Housewives to Activists: Women and the Division of Political Labor in the Boston Antibusing Movement'. In Kathleen M. Blee (ed.) No Middle Ground: Women and Radical Protest. New York: New York University Press, pp.251288. 